\title{
Natural history of chronic Chagas' heart disease: prognosis factors
}

\author{
Heart Institute, Hospital das Clínicas da Faculdade de Medicina \\ da Universidade de São Paulo - São Paulo, Brazil
}

Chronic Chagas' disease shows several progression modes. Usually, the different clinical syndromes manifest themselves together, however, isolated forms can occur. Cardiac arrhythmias, which are very frequent, are present in about $50 \%$ of patients. The cardiac damage manifests itself later, with the emergence of heart failure. Thromboembolism can occur in both pulmonary and systemic circulation. Pulmonary embolism is the most frequent, appearing in more advanced phases of heart disease. Sudden death is the fatal outcome of these patients. It predominates in males and it generally occurs in a disease stage when patients have their highest productivity. The presence of serious ventricular arrhythmias, conduction disturbances in the eletrocardiogram, and heart failure, provide an unfavorable prognosis.

UNITERMS: Chronic Chagas' disease. Natural history. Prognostic.

$\mathrm{T}$ he chronic Chagas' disease cardiomyopathy was first studied in 1922 by Chagas and Villela (5). The chronic cardiomyopathy comprises the most important clinical form of the disease. Those authors have been able to establish conclusions very clear about its clinical picture, progression and disease prognosis since that time.

After the acute phase, which lasts about two months, the patient can remain indefinitely in the indeterminate form (11), or the chronic Chagas' disease can manifests

\author{
Address for correspondence: \\ Charles Mady \\ Instituto do Coração - Hospital das Clínicas da FMUSP \\ Av. Dr. Enéas de Carvalho Aguiar, 44 \\ São Paulo - São Paulo - Brasil - CEP 05403-000
}

itself after some decades of progression. The chronic Chagas' disease displays different cardiac manifestations with the presence of arrhythmias and/or conduction disturbances, heart failure, thromboembolism and sudden death are the most common (table 1). These clinical syndromes can be manifested separately, but they usually surface together.

Table 1

Cardiac manifestations of chronic Chagas' disease

- Arrhythmias and/or conduction disturbance

- Heart failure

- Thromboembolism

- Sudden death 


\section{ARRHYTHMIAS}

One of the chronic Chagas' disease attributes is the great variety of cardiac rhythm disturbances present in about $50 \%$ of the patients. Cardiac rhythm changes are the most frequent clinical form of the disease.

The chronic Chagas' cardiomyopathy, with its diffuse, progressive and fibrotic characteristics, is an excellent anatomic and pathological background for the re-entry's phenomenon with the consequent the occurrence of arrhythmias.

Andrade (1), studied the morphological basis of the cardiac arrhythmias in chronic Chagas' disease. He discusses that all the heart conduction system can be assailed, including the sinus-atrial node, atrioventricular nodal, His' bundle, His' bundle branches and Purkinje's fibers.
One can split the arrhythmias in three groups: extrasystoles, bradyarrhythmias and tachyarrhythmias.

The most frequent electrocardiographic changes are ventricular extrasystoles, complete right bundle branch block, antero-septal divisional block of left branch, several grades of atrioventricular blocks and changes in the ventricular repolarization (3). The ventricular extrasystoles are a common finding, mainly the polymorphic group of extrassystoles.

Frequently, one observes ventricular extrasystoles associated with divisions and branches blocks. The presence of the complete right branch block is usually associated to anteroseptal divisional block of left branch. Nacruth and col. (13), in a retrospective study of 143 patients, found the predominance of complete right branch block associated to anteroseptal divisional block of left branch (BRDe BDAS) $(24,47 \%)$ followed by an isolated $\operatorname{BCRD}(13,28 \%)$ and BDAS $(9,7 \%)$.
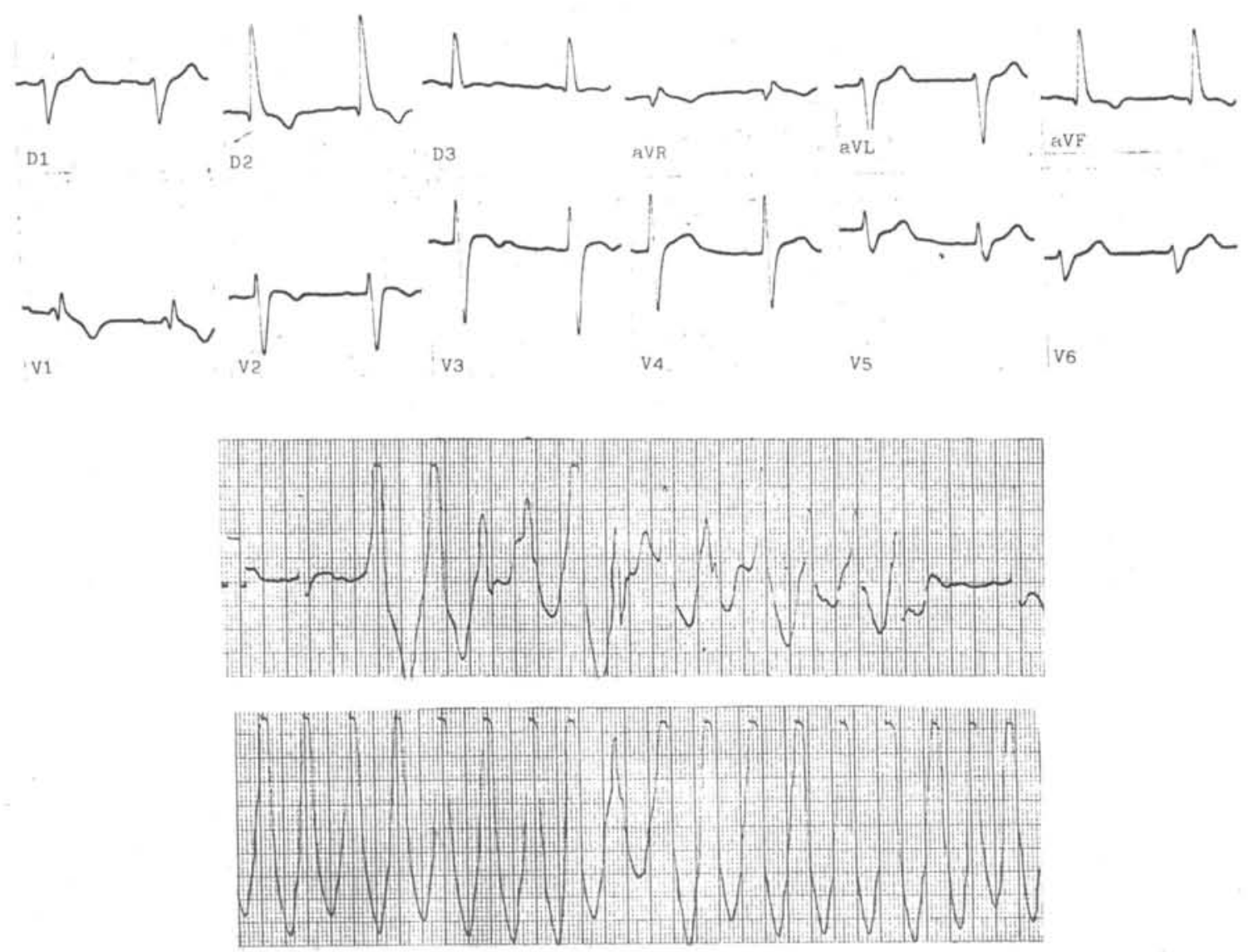

Figure 1. A 20 year-old male patient with Chagas' disease complained of palpitations during physical efforts. He also reported two syncope attacks during practicing sports. He had an unremarkable chest X-ray. His conventional EKG presented an AQRS axis deviation to the right and a BCRD. The Holter monitoring showed both sustained and nonsustained ventricular tachycardia. The patient died suddenly death during physical effort about one month after the identification of the ventricular tachyarrhythmia. He was taking amiodarone. 

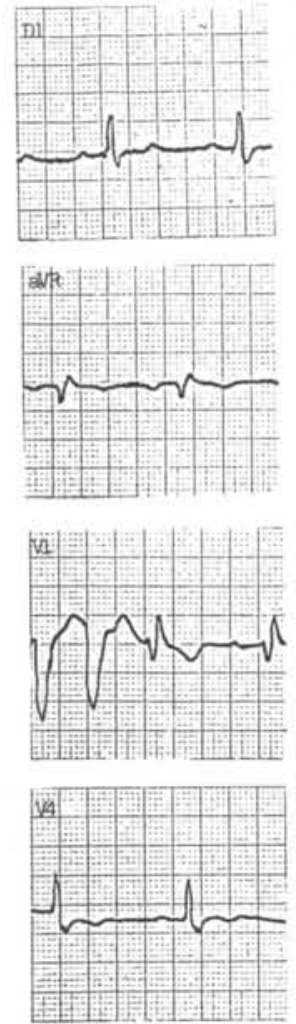
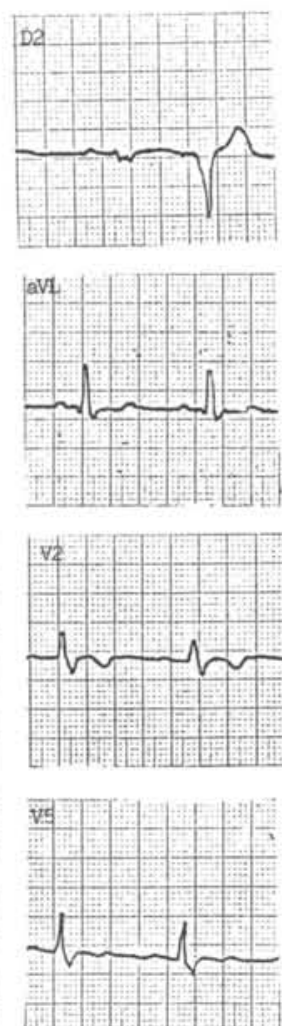
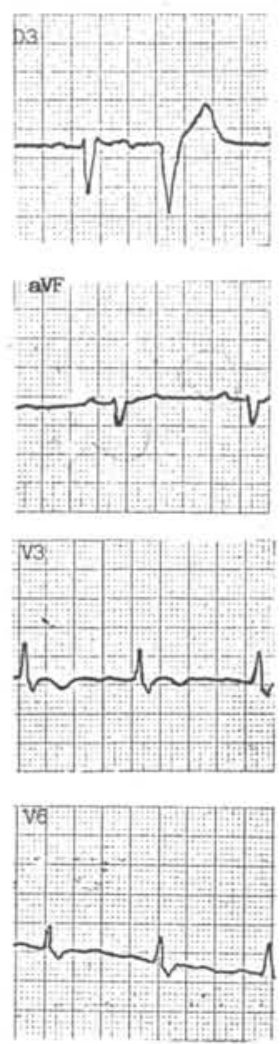

D]
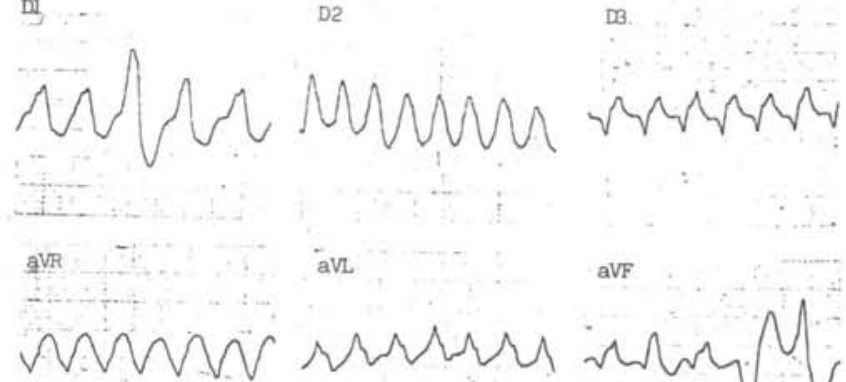

avl.

aVF
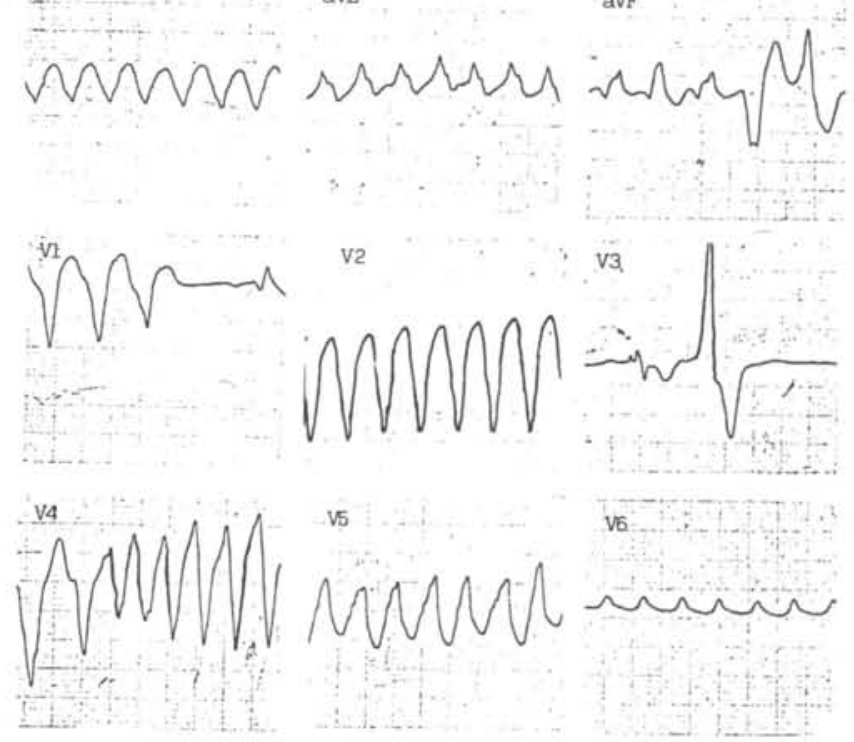

Figure 2. A 36 year-old male patient with Chagas' disease with a basal line EKG (A) showing an incomplete and complete right bundle branch block and ventricular extrasystoles suggesting inactive areas;

(B) Sustained ventricular tachycardia. Echocardiogram showed segmental disjunction and lower middle-basal akinesis.

The arrhythmias usually provoke palpitations and vertigo and depending on the severity, the arrhythmias can cause fainting, syncope and seizures due to low cardiac and cerebral blood flow.

In this context, the ventricular tachyarrhythmias have a vital importance in the occurrence of sudden death (figure 1).

In general, ventricular tachyarrhythmias come along with cardiomegaly and branch and/or divisional blocks. However, ventricular arrhythmias is hardly observed in subjects with a normal cardiac area and/or a previous electrocardiogram without a conduction disturbance (Figure 2).

Some noninvasive cardiac tests, such as Holter monitoring, ergometric test and echocardiogram, help on evaluation the arrhythmias. The Holter test is the most sensitive to detect arrhythmias. Ergometric test is less sensitive than the Holter test. The ergometric test can sometimes detect tachyarrhythmias, being very useful in those patients with physical effort-related symptoms. The effort test, in some occasions, identifies patients with Chagas' disease predisposed to sudden death. Electrophysiological studies provide important information for the evaluation of the development and conduction disturbance of the stimulus. These studies are able to induce ventricular tachycardia in some patients. According to De Paola (6), it is possible to induce the same arrhythmia in $81 \%$ of the patients with chronic Chagas' disease and recurrent ventricular tachycardia. Besides the clinical arrhythmia induction, the electrophisiological study localizes the arrhythmogenic focus of the ventricular tachycardia through the endocardic mapping. The endocardic mapping of the arrhythmogenic focus during the electrophisiological study has been accomplished nowadays with promising results (7). 


\section{HEART FAILURE}

The histopathological findings in cardiac chronic Chagas' disease are different from the those found in the acute phase and in the myocarditis of other etiologies. The anatomic background of chronic Chagas' disease is a progressive, fibrotic and diffuse chronic myocarditis, that slowly destroys the myocardial fibers leading to heart failure.

In general, the heart failure manifests itself between thirty and forty years of age. However, it can manifest itself in any progressive period. The heart failure usually appears later when compared to the arrhythmias. It develops slowly and it rarely develops in a quick way with haemodynamic deterioration in a short period of time.

The heart failure is global, but manifestations of right heart failure can be predominant, and they are one peculiarity of heart failure from Chagas' etiology. It is interesting to observe the contrast between the degree of systemic passive congestion, and the few clinical manifestations of the left ventricular failure. We frequently observe patients with marked jugular turgescence, painful hepatomegalia and lower limb edema, bearing quite well the dorsal decubitus.

Nocturnal paroxysmal orthopnea as well dyspnea are not observed with the same frequency as they are found in heart failure of other etiologies. The hepatomegalia is manifested early and the patient's main complaint is usually pain in the right hypochondrium (19).

At this stage, it is possible to observe large cardiomegalies and electrocardiographic changes in nearly all patients. The echocardiogram shows hypokinetic areas, dyskinetic, vortex lesion, intracavitary thrombus and/or diastolic dysfunction of left ventricle.

In the follow-up of a patient with chronic Chagas (5) disease, it is observed that, when the heart failure starts to manifest, the prognosis grows worse with an evident increase in the morbidity and mortality.

It is relatively frequent the presence of ventricular arrhythmias in patients with heart failure, particularly the ventricular extrasystoles and sustained and not-sustained ventricular tachycardia.

\section{THROMBOEMBOLISM}

The occurrence of thromboembolism in chronic Chagas' disease is frequent in systemic and pulmonary circulations, however it is more frequent in the pulmonary one. It usually occurs in advanced phases of heart failure, but is also observed in the initial phases of heart disease.

The great importance of vortex lesion in thromboembolic phenomenon occurrence is pointed out. The vortex lesion or apex lesion, which is characteristic of chronic Chagas' disease, consists of depopulation and atrophy of the myocardium of the vortex region, predisposing to the thrombus formation. The prevalence of apical lesion in chronic Chagas' disease is variable and it can oscillate around $50 \%$ to $80 \%$ of patients, being more frequent in patients with heart failure.

Other factors, such as circulatory stasis that is present in heart failure and atrial fibrillation, it also predisposes to thromboembolism.

Andrade and Andrade (2) studied 208 patients and found thrombosis in the following places: right atrium $(56,2 \%)$, apex of the left ventricle $(47,1 \%)$, left atrium and apex of the right ventricle $(12,9 \%)$, mural endocardium of the left ventricle $(10,6 \%)$ and of the right ventricle $(1,4 \%)$. It was not observed intracavitary thrombi in 50 patients $(24 \%)$. It draws one's attention the high incidence of this phenomenon in these patients.

Oliveira (14) upon analysing 515 patients with cardiac thrombosis, observed that the left cardiac chambers were affected more frequently, being the ventricular cavity the most affected. Right chamber thrombosis was less frequent, with predominance of atrial thrombosis.

The presence of thrombosis is observed through the echocardiogram or through ventriculographic studies and it should be suggested by the presence of hypokinetic or akinetic areas.

\section{SUDDEN DEATH}

The high prevalence of sudden death in chronic Chagas' disease is known since a long time ago in endemic regions and it was remarked by Carlos Chagas (4) in 1912.

The prevalence of sudden death in medical literature is variable. Porto (17) detected sudden death in $37,5 \%$ of his patients. Köberle (8) observed that $30 \%$ of his patients with Chagas' disease who were submitted to an autopsy, died from sudden death. Lopes and col (10) noticed that $12,6 \%$ of his patients with Chagas' who were submitted to an autopsy, died from sudden death.

Sudden death can be either unexpected or not. The unexpected sudden death occurs in those patients who are well, asymptomatic, and it is not very frequent. The 
expected sudden death occurs in patients in whose previous symptoms could be observed, and, in most of the time, with advanced heart disease. It predominantly assails men, and occurs, more frequently, between the third and fifth decades of life.

The symptoms of patients who died suddenly are the consequences of the presence of ventricular arrhythmias, manifesting themselves by palpitations, vertigo, lipothymia and Stokes-Adams. Sustained ventricular tachycardia is the most common arrhythmia, progressing to ventricular fibrillation.

Generally, sudden death occurs during physical activity. There are family histories of sudden death in more than $80 \%$ of the patients (18).

There are some predisposing factors to sudden death: chronic myocarditis, fibrosis, conduction system change, apical lesion (arrhythmogenic source), sex and age. In fact, several clinical syndromes of chronic Chagas' disease predispose to sudden death.

\section{PROGNOSTIC FACTORS}

The chronic Chagas' disease shows a slow and unrelenting progression. It develops fast sometimes, causing important clinical manifestations in young people. The earlier the clinical becomes manifested, the worse the prognosis will be.
Some factors influence the prognosis of chronic form of Chagas' disease in a negative way: heart failure, arrhythmias such as ventricular extrasystoles, polymorphic or cluster fibrillation, atrial flutter, ventricular tachycardia, total atrioventricular block and inactive areas (19).

The presence of failure and/or sustained ventricular tachycardia is considered the worst prognostic factor.

The electrocardiogram shows a real prognostic value in the chronic Chagas' disease. A normal electrocardiogram indicates a good prognosis. The presence of complete right branch block does not indicate a bad prognosis, however the situation grows worse when the block is associated to axis deviation to the left. The complete left branch block, which occurs less frequently, indicates a bad prognosis (17). Similar results were observed by Nacruth and cols. (13).

Gender influences the disease's natural history. Generally, the cardiac damage is greater in men, and that can explain the worst progression in this sex (15).

The other factor is age. It has great importance, because the majority of the patients who die, are in the highest productive phase of their lives. Laranja and col. (9), analyzed 200 patients who died and observed that $55 \%$ of them were between 21 and 40 years of age.

We judge that the suitable knowledge of those prognostic factors helps us intensely, both in social and professional words of advice and in the therapeutic orientation of the patients.

\section{Resumo}

A cardiopatia chagásica crônica apresenta diversas formas de evolução. Habitualmente, as síndromes clínicas manifestam-se conjuntamente, porém podendo ocorrer formas isoladas. As arritmias, muito freqüentes, aparecem em cerca de $50 \%$ dos pacientes. O acometimento cardíaco, manifesta-se mais tardiamente, com manifestaçōes de insuficiência cardiaca. O tromboembolismo pode ocorrer na circulação pulmonar e sistêmica, sendo a embolia pulmonar a mais freqüente, aparecendo 等 e ocorrendo, geralmente, em fase de maior produtividade dos pacientes. A presença de arritmias ventriculares importantes, distúrbios de condução ao eletrocardiograma e insuficiência cardiaca
proporcionam prognóstico desfavorável. 


\section{REFERENCES}

1. ANDRADE, Z.A. - Bases morfológicas das arritmias na miocardite chagásica. In: Cançado, Jr. \& Chuster, M. Cardiopatia chagásica. Belo Horizonte, Fundação Carlos Chagas, 1985. p.79-90.

2. ANDRADE, Z.A. \& ANDRADE, S.G. - Trypanosoma cruzi e doença de Chagas. In: Brener, Z.; Andrade, Z. Patologia: 199-248, 1979.

3. ARTEAGA-FERNÁNDEZ, E.; PEREIRA BARRETTO, A.C.; MADY, C.; IANNI, B.M.; BELLOTTI, G. \& PILEGGI, F. - O eletrocardiograma em pacientes com reações sorológicas positivas para doença de Chagas. Estudo de 600 casos. Arq Bras Cardiol 44:333-7, 1985.

4. CHAGAS, C. - O mal de Chagas. Arq Soc Med Cir São Paulo 3:34-66, 1912.

5. CHAGAS, C. \& VILlELA, E. - Forma cardíaca da tripanosomíase americana. Mem Inst Oswaldo Cruz 14:561, 1922.

6. DE PAOLA, A.A.V. - Estimulação ventricular programada em pacientes com cardiopatia chagásica crônica e taquicardia ventricular. São Paulo, 1991; 61 p. [Tese de Livre Docência, Escola Paulista de Medicina].

7. DE PAOLA, A.A.V.; BALBAS, C.E.B.; CASTIGLIONI, M.L.V. et al. - Mapeamento radioisotópico do foco arritmogênico em portadores de cardiopatia chagásica crônica e tacquicardia ventricular sustentada. Arq Bras Cardiol 60:373-6, 1993.

8. KÖBERLE, F. - Cardiopatia chagásica. O Hospital 53:31146, 1958 .

9. LARANJA, F.S.; DIAS, E.; NOBREGA, G. \& MIRANDA, A. - Chagas disease. A clinical, epidemiologic and pathologic study. Circulation 14:1035-60, 1956.

10. LOPES, E.R.; CHAPADEIRO, E.; ALMEIDA, H.O.; ROCHA, A. \& ROCHA, A. - Contribuição ao estudo da anatomia patológica dos corações de chagásicos falecidos subitamente. Rev Soc Bras Med Trop 9:269-82, 1975.

11. MADY, C. \& DÉCOURT, L.V. - A forma indeterminada da doença de Chagas. Arq. Bras Cardiol 36:143-5, 1981.

12. MADY, C.; PEREIRA BARRETTO, A.C.; IANNI, B.M.; LOPES, E.R. \& PILEGGI, F. - Right ventricular endomyocardial biopsy in undetermined form of Chagas' disease. Angiology 35:755-9, 1984.

13. NACRUTH, R.S.; BENINI, N.; BONGIOVANI, A.C. \& HASSAN, N. - Bloqueios divisionais na doença de Chagas. Rev Soc Bras Med Trop 20:19, 1987.

14. OLIVEIRA, J.S.M. - Tromboses cardíacas e tromboembolismo. In: Cançado, Jr. \& Chuster, M. Cardiopatia chagásica. Belo Horizonte, Fundação Carlos Chagas 1985; cap.7:54-9.

15. PEREIRA BARRETTO, A.C.; ARTEAGA, E.; MADY, C.; IANNI, B.M.; BELLOTTI, G. \& PILEGGI, F. - Sexo masculino. Fator prognóstico na Doença de Chagas. Arq Bras Cardiol 60:225-27, 1993.

16. PEREIRA BARRETTO, A.C.; MADY, C.; ARTEAGAFERNÁNDEZ, E. et al, - Right ventricular endomyocardial biopsy in chronic Chagas' disease. Am Heart J 111:307-12, 1986.

17. PORTO, C.C. - Contribuição do eletrocardiograma no prognóstico e evolução da Doença de Chagas. Belo Horizonte, 1963; 281 p. [Tese de Doutoramento. Faculdade de Medicina da UFMG].

18. PRATA, A.; LOPES, E.R. \& CHAPADEIRO, E. - Morte súbita. In: Cançado, Jr. \& Chuster, M. Cardiopatia chagásica. Belo Horizonte, Fundação Carlos Chagas 1985. p. 114-20.

19. RASSI, A.; TRANCHESI, J. \& TRANCHESI, B. - Doença de Chagas. In: Veronesi, R. Doenças infecciosas e parasitárias. 7 ed. Rio de Janeiro, Guanabara Koogan. p. 691-706. 